\title{
Does electrodiagnostic evidence correlate with mood and function in patients with a pre-diagnosis of carpal tunnel syndrome?
}

\author{
Özge Keniş-Coşkun, ${ }^{1}$ Evrim Karadağ-Sayg1, ${ }^{2}$ Tuğba Özsoy, ${ }^{2}$ Esra Giray, ${ }^{2}$ Başak Mansız-Kaplan, ${ }^{3}$ Kaan Kora ${ }^{4}$ \\ ${ }^{1}$ Department of Physical Medicine and Rehabilitation, Kartal Dr. Lütfi Kırdar Training and Research Hospital, İstanbul, Turkey \\ ${ }^{2}$ Department of Physical Medicine and Rehabilitation, Medical Faculty of Marmara University, İstanbul, Turkey \\ ${ }^{3}$ Department of Physical Medicine and Rehabilitation, Ankara Physical Therapy and Rehabilitation Research and Training Hospital, Ankara, Turkey \\ ${ }^{4}$ Department Psychiatry, Medical Faculty of Marmara University, İstanbul, Turkey
}

Received: April 2016 Accepted: October 2016

\begin{abstract}
Objectives: This study aims to investigate if function and mood involvement correlate in female patients who have a pre-diagnosis of carpal tunnel syndrome (CTS) and its correlation with physical examination and electrodiagnostic findings.

Patients and methods: A total of 170 patients between the ages of 18-65 who applied to Physical Medicine and Rehabilitation outpatient clinics with CTS symptoms between May 2014 and December 2015 were enrolled. The mean age of patients was $44.6 \pm 11$ years. Before electrophysiological testing (electromyography; EMG), Disabilities of the Arm, Shoulder and Hand questionnaire (QuickDASH), Beck Depression Inventory, Tinnel, Phalen and Durkan tests, grip and pinch strength measurement by JAMAR hand dynamometer were performed. The patients also used a Visual Analog Scale (VAS) to determine the severity of their symptoms during the day and at night.

Results: In 98 patients (57.6\%) the diagnosis of CTS was confirmed by EMG, while 72 patients (42.4\%) had normal electrodiagnostic findings. In patients who had normal EMG, Beck Depression Inventory and QuickDASH scores were not significantly different from the patients who had an electrodiagnosis of CTS. Pain experienced in the night was significantly higher in patients who had an electrodiagnosis of CTS, and these patients had significantly higher Beck Depression Inventory and QuickDASH scores.

Conclusion: The lack of electrodiagnostic evidence in patients who have CTS symptoms does not show that function and mood are not affected in these patients. However, mood is significantly affected in patients with severe CTS.
\end{abstract}

Keywords: Carpal tunnel syndrome; function; mood.

Carpal tunnel syndrome (CTS) is the entrapment of the median nerve underneath flexor retinaculum at the wrist level. Primary features of CTS include pain in the hand, tingling, pain or numbness in the distal distribution of the median nerve. Many patients report symptoms outside the distribution of the median nerve. There may be numbness or pain in ulnar digits, forearm, elbow, arm and also shoulder. Symptoms tend to be worse at night and clumsiness is reported during the day with activities. ${ }^{[1,2]}$

Diagnostic criteria for CTS have been defined a number of times in the literature. Criteria for the clinical diagnosis of CTS can include a characteristic history alone, ${ }^{[3]}$ a combination of history and physical examination findings, ${ }^{[4]}$ a characteristic history combined with electrodiagnostic findings suggestive of CTS ${ }^{[5]}$ and electrodiagnostic data alone. ${ }^{[6]}$ The reason for the need for various diagnostic criteria is that CTS requires not only an electrodiagnostic finding, rather a clinical picture, and patients must also be evaluated thusly. If the patient has clinical symptoms and signs of CTS in the absence of electrodiagnostic abnormalities, they should be evaluated as if they have CTS, given the history and physical examination, and the clinical evidence of CTS. ${ }^{[7]}$

Previous studies have shown that, CTS patients have higher rates of anxiety, depression, current substance abuse and somatoform pain disorders. ${ }^{[8]}$ In these patients, depression and anxiety were correlated with diminished sensation, hand weakness, thenar atrophy

Corresponding author: Özge Keniş-Coşkun, MD. Kartal Dr. Lütfi Kırdar Ĕgitim ve Araştırma Hastanesi, Fiziksel Tıp ve Rehabilitasyon Kliniği, 34890 Cevizli, Kartal, İstanbul, Turkey. e-mail: ozgekenis@gmail.com 
and hand pain. ${ }^{[9]}$ There are also studies showing that there is a relationship between CTS and functional involvement. ${ }^{[10,11]}$ But there are no studies evaluating if patients who do not have electrophysiological confirmation of their symptoms are also affected functionally and psychologically. From a different perspective, one can also ask whether psychological and functional involvement can help a clinician reach a more definite diagnosis of CTS, particularly when an electrodiagnostic test is unable to be performed. This presents an important question in the current clinical setting of Turkey, where some physicians do not have access to an EMG laboratory to confirm their diagnoses, and others refer all the patients with clinical symptoms of CTS to electromyography (EMG) laboratories for confirmation, even without taking a proper clinical background and a proper physical examination.

In the present study, we aimed to evaluate if there is a relationship between electrodiagnostic evidence of CTS and function and mood in a population of patients who presented with a clinical picture of CTS and were referred to an EMG lab for diagnostic confirmation.

\section{PATIENTS AND METHODS}

This prospective study was carried out between May 2014 and December 2015. The Ethics Committee of Marmara University approved the project (70737436-050.06.04-1300241724) and informed consent was obtained from all the patients. The study was conducted in accordance with the principles of the Declaration of Helsinki.

Two hundred twelve participants between the ages of 18-65 with a pre-diagnosis of CTS who had been referred to our EMG laboratory for a confirmation of their diagnoses were included in the study. Patients with systemic diseases, which can also cause CTS or CTS like symptoms such as diabetes, hypothyroidism etc. were excluded from the study. Patients with left hand dominance, male patients and patients who had additional electrodiagnostic abnormalities were left out in the statistical analyses (Figure 1). Patients underwent a physical examination by one physician for Tinnel's, Phalen's and Durkan's tests. Nerve conduction studies involving median and ulnar nerve sensory nerve action potentials (SNAP) and compound muscle action potentials (CMAP) were performed and evaluated by another, blinded physician. The diagnoses of mild, moderate or severe CTS were given according to American Association of Neuromuscular \& Electrodiagnostic Medicine (AANEM) guidelines. ${ }^{[12]}$

According to these guidelines, prolonged (relative or absolute) sensory latencies with normal motor studies are considered mild CTS. Prolonged latencies in both motor and sensory nerve are considered moderate CTS. In addition to prolonged latencies, an absence of SNAP or CMAP potentials and/or a needle EMG of abductor policies brevis muscle with fibrillation potentials or motor unit potential changes is considered as severe CTS. A prolonged latency is considered above $4.0 \mathrm{~m} / \mathrm{s}$.

A total of 170 patients were included in the final statistical analyses. The mean age of patients was $44.6 \pm 11$ years, (range 18 to 65 years). $24.2 \%$ of the patients were actively working in a job while $75.8 \%$ were housewives. One hundred and nine patients (64.1\%) had bilateral symptoms, while 23 patients (\%13.5) had left-sided, 38 patients (\%22.4) had right-sided symptoms. Mean symptom time was 25 (range, 1 to 240) months.

Patients' level of pain and numbness were measured with Visual Analog Scale (VAS) and it was separately measured for daytime and nighttime pain. All the patients were required to fill in Quick Disabilities of Arm, Shoulder and Hand score (QuickDASH) for a functional outcome and Beck Depression Inventory (BDI) to assess their mood. QuickDASH uses 11 items to measure physical function and symptoms in people with any or multiple musculoskeletal disorders of the upper limbs. The action-specific parts of QuickDASH were not applied. It has been translated into Turkish and validated in CTS patients. ${ }^{[13]}$ The BDI is a 21-question multiple-choice self-report inventory and is composed of items relating to symptoms of depression such as

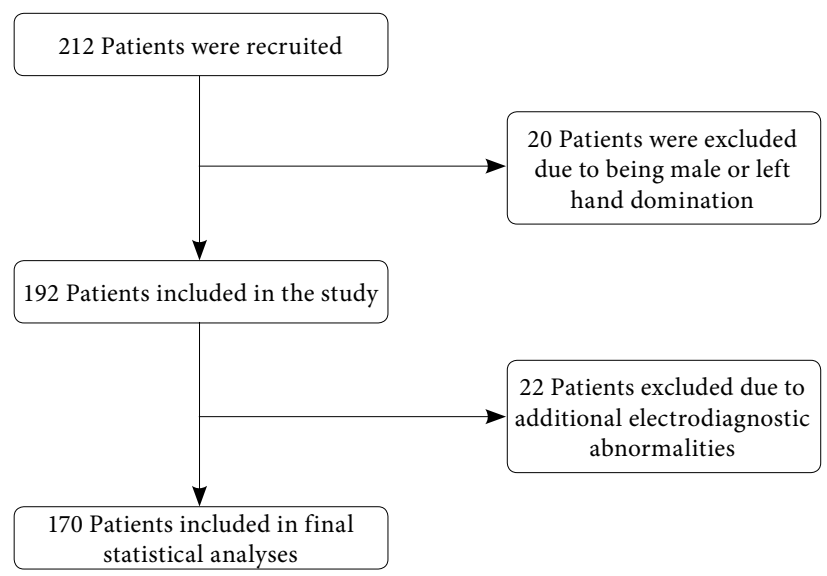

Figure 1. Flow diagram of the study. 
Table 1. Physical examinations and electromyography

\begin{tabular}{|c|c|c|c|c|c|c|c|c|}
\hline & \multicolumn{2}{|c|}{ Tinel } & \multicolumn{2}{|c|}{ Phalen } & \multicolumn{2}{|c|}{ Durkan } & \multicolumn{2}{|c|}{ Electromyography } \\
\hline & $\mathrm{n}$ & $\%$ & $\mathrm{n}$ & $\%$ & $\mathrm{n}$ & $\%$ & $\mathrm{n}$ & $\%$ \\
\hline \multicolumn{9}{|l|}{ Positive } \\
\hline Right & 26 & 15.3 & 24 & 14.1 & 27 & 15.9 & 19 & 11.2 \\
\hline Left & 21 & 12.4 & 24 & 14.1 & 21 & 12.4 & 13 & 7.6 \\
\hline Bilateral & 64 & 37.6 & 73 & 42.9 & 70 & 41.2 & 66 & 38.8 \\
\hline Negative & 59 & 37.4 & 49 & 28.8 & 52 & 30.6 & 72 & 42.4 \\
\hline Total & 170 & & 170 & & 170 & & 170 & \\
\hline
\end{tabular}

hopelessness and irritability, cognitions such as guilt or feelings of being punished, as well as physical symptoms such as fatigue, weight loss and lack of interest in sex. This scale has also been validated in Turkish. ${ }^{[14]}$

\section{Statistical analysis}

Statistical significance is defined by $p$ values less than 0.05. All analyses were performed using SPSS for Windows version 16.0 software (SPSS Inc., Chicago, IL, USA). Normal distribution of data was examined using Kolmogorov-Smirnov and Shapiro-Wilkins tests. Descriptive variables were expressed as mean, median, minimum and maximum values. Variables normally distributed between groups were analyzed using Student's t-test, non-normally distributed variables using Mann-Whitney $U$ test. Analysis within the groups was done using Wilcoxon test. The correlations were analyzed with Spearman correlation coefficients. A $p$ value of $<0.05$ was considered statistically significant

\section{RESULTS}

During the physical examinations, 64 patients (37.6\%) had bilateral positive Tinnel tests, while 59 patients (34.7\%) had bilateral negative Tinnel tests. Seventy-three patients $(42.9 \%)$ had bilateral positive Phalen findings, while 49 patients $(28.8 \%$ ) had negative findings. Similarly, Durkan's tests were positive bilaterally in 70 patients (41.2\%) while it was bilaterally negative in 52 patients (30.6\%). When Tinnel, Phalen and Durkan's tests were correlated with the EMG, it was shown that all tests were mild to moderately correlated ( $\mathrm{r}=0.275, \mathrm{r}=0.427, \mathrm{r}=0.284$, respectively). Phalen test were the most sensitive $(71 \%, \mathrm{p}=0.02)$ and the most specific $(75.5 \%, \mathrm{p}=0.01)$ amongst the physical examination tests (Table 1 ).

In 98 patients $(57.6 \%)$, the diagnosis of CTS was confirmed by EMG, while 72 patients $(42.4 \%)$ had normal electrodiagnostic findings. Thirty-eight patients had mild CTS (22.4\%), 47 patients had moderate CTS $(27.6 \%)$ and 13 patients (7.6\%) had severe CTS. Sixty-six of the patients had electrodiagnostic findings of bilateral CTS (38.8\%). Patient reported symptoms showed a weak correlation with the electrodiagnostic findings $(r=0.249)$, however 55 of the patients who had bilateral symptoms (50.5\%) were shown to be positive in EMG (Table 2).

In patients who had normal EMG, BDI and QuickDASH scores were not significantly different from the patients who had an electrodiagnosis of CTS. Pain experienced in the night was significantly higher in patients who had an electrodiagnosis of CTS, and these patients had significantly higher BDI and QuickDASH scores (Table 3). When BDI scores were further evaluated, $53.8 \%$ of the patients who had severe CTS had moderate depression, while this

Table 2. Patients symptoms and their electromyography findings

\begin{tabular}{|c|c|c|c|c|c|c|c|c|c|}
\hline & & & \multicolumn{6}{|c|}{ Positive } & \multirow{3}{*}{$\frac{\text { Total }}{\mathrm{n}}$} \\
\hline & \multicolumn{2}{|c|}{ Negative } & \multicolumn{2}{|c|}{ Left } & \multicolumn{2}{|c|}{ Right } & \multicolumn{2}{|c|}{ Bilateral } & \\
\hline & $\mathrm{n}$ & $\%$ & $\mathrm{n}$ & $\%$ & $\mathrm{n}$ & $\%$ & $\mathrm{n}$ & $\%$ & \\
\hline \multicolumn{10}{|l|}{ Positive } \\
\hline Left & 13 & 56.5 & 0 & 0 & 7 & 30.4 & 3 & 13 & 23 \\
\hline Right & 19 & 50 & 10 & 26.3 & 1 & 2.6 & 8 & 21.1 & 38 \\
\hline Bilateral & 40 & 36.7 & 9 & 8.3 & 5 & 4.6 & 55 & 50.5 & 109 \\
\hline Total & 72 & 42.4 & 19 & 11.2 & 13 & 7.6 & 66 & 38.8 & 170 \\
\hline
\end{tabular}


Table 3. Beck and Disabilities of Arm, Shoulder, and Hand scores between groups according to their electrodiagnostic results

\begin{tabular}{|c|c|c|c|c|c|c|c|c|c|}
\hline & \multicolumn{9}{|c|}{ Electromyography } \\
\hline & \multicolumn{2}{|c|}{ Normal (n=72) } & \multicolumn{2}{|c|}{ Mild CTS (n=38) } & \multicolumn{2}{|c|}{ Moderate CTS $(\mathrm{n}=47)$} & \multicolumn{2}{|c|}{ Severe CTS $(n=13)$} & \multirow[b]{2}{*}{$p$} \\
\hline & Mean \pm SD & Min-Max & Mean \pm SD & Min-Max & Mean \pm SD & Min-Max & Mean \pm SD & Min-Max & \\
\hline BDI & $15.9 \pm 10.6$ & $0-46$ & $16.3 \pm 8.2$ & $3-33$ & $16.6 \pm 8.7$ & $0-38$ & $18.9 \pm 8.3$ & $4-32$ & 0.668 \\
\hline DASH & $52.9 \pm 20.6$ & $4.54-90.9$ & $56.8 \pm 18$ & $22.7-86.4$ & $55 \pm 18.3$ & $9.1-90.9$ & $59.6 \pm 21$ & $27.3-90.9$ & 0.593 \\
\hline Day time pain VAS & $5.43 \pm 2.8$ & $0-10$ & $5.95 \pm 2$ & $2-10$ & $6.3 \pm 1.8$ & $1-10$ & $6.5 \pm 2$ & $3-10$ & 0.408 \\
\hline Night-time pain VAS & $5.86 \pm 3$ & $0-10$ & $6.9 \pm 2.4$ & $0-10$ & $7.55 \pm 2.5$ & $0-10$ & $7.54 \pm 3$ & $0-10$ & 0.006 \\
\hline
\end{tabular}

CTS: Carpal tunnel syndrome; SD: Standard deviation; Min: Minimum; Max: Maximum; BDI: Beck Depression Inventory; DASH: Disabilities of Arm, Shoulder, and Hand; VAS: Visual Analog Scale.

ratio was $27.8 \%$ for the patients who had normal electrodiagnostic findings ( $\mathrm{p}>0.05)$.

\section{DISCUSSION}

This study shows that a proper anamnesis and a proper physical examination are cornerstones for diagnosis in CTS. Pain is the main influential factor on both mood and function in patients with CTS. However, mood does not significantly differ in patients with electrodiagnostically confirmed CTS, compared to patients without electrodiagnostic evidence.

Based on the results of the present study, it can be said that with a proper examination and a proper anamnesis, one can predict a person's electrodiagnostic outcome, when one does not have access to EMG. A key point in the anamnesis is that the probability of a patient having CTS is much higher if the symptoms are bilateral. Also, when physical examination findings are bilateral, the probability of CTS also increases significantly. Therefore, if there are bilateral symptoms and physical examination findings, a treatment can be initiated if there is no access to an EMG laboratory, or a contradicting factor against doing an EMG investigation.

Pain has shown to be influential on function and mood in patients who had a diagnosis of CTS. ${ }^{[10,11]}$ In this study, VAS scores were positively correlated with BDI and QuickDASH scores, similar to previous studies. Additionally, our study revealed that if the patients have symptoms of CTS but no electrodiagnostic evidence of it, their function and mood are still affected. Even though the findings of this study sound surprising, there are previous studies with similar outcomes. In another study including 98 patients who were referred to an EMG laboratory for testing for CTS, patients without electrodiagnostic evidence of CTS had similar symptoms of depression, heightened illness concern and catastrophic thinking It has also been shown that non-specific upper extremity complaints are significantly affected in psychological aspects, which in turn affects mood. ${ }^{[15]}$ A large study which involved a total of 886 patients also found that patients without electrodiagnostic evidence have poor mental health and do not differ from patients who have electrodiagnostically confirmed CTS. ${ }^{[16]}$ Therefore, even when the involvement of median nerve cannot be solidified with electrodiagnosis, physicians must approach patients knowing that there are serious functional and mood involvement.

The theoretical reasons for a negative study in a patient with CTS are the condition being too mild, affecting too few nerve fibers; symptoms due to intermittent ischemia, which is fully reversible and testing occurring after innervation of sensory nerve action potential..$^{[17]}$ Another reason for high negative electrodiagnostic findings in this study can be that the finer methods to define milder cases of CTS were not used in the patients. A previous study shows that use of a combined sensory index increases the chance of diagnosing mild CTS earlier in the course of the disease. ${ }^{[18]}$ This method was not applied to the participants involved in this study, which may have caused a higher negative electrodiagnostic outcome.

The lack of significant differences in mood between patients who have normal electrodiagnostic findings and patients who had confirmed CTS might also have been the result of a higher BDI score all over our patient population. In a similar study, the mean BDI score of the patients was 10.38 in nonneurological hand pain group and 5.38 in patients with CTS $^{[19]}$ but in our study it was above 15 for all groups. There is no data to show that BDI scores are higher in Turkish population, or there are no baseline data for depression of the population that are referred to our EMG laboratory. This area can be further elaborated on to define if the patients referred to an EMG laboratory in Turkey are overall more depressed than a control group. Furthermore, the BDI scores of 
patients who have severe CTS are significantly higher than patients without electrodiagnostic evidence of CTS. The number of patients who are diagnosed with severe CTS might be too low to define a significant difference in the overall CTS group. A study with a different design to include more severe CTS patients may show the real involvement of mood in these patients.

In conclusion, this study has shown that the lack of electrodiagnostic evidence in patients who have CTS symptoms does not necessarily show that function and mood is not affected in these patients. However, mood is significantly affected in patients with severe CTS.

\section{Declaration of conflicting interests}

The authors declared no conflicts of interest with respect to the authorship and/or publication of this article.

\section{Funding}

The authors received no financial support for the research and/or authorship of this article.

\section{REFERENCES}

1. Ibrahim I, Khan WS, Goddard N, Smitham P. Carpal tunnel syndrome: a review of the recent literature. Open Orthop J 2012;6:69-76.

2. Stevens JC, Smith BE, Weaver AL, Bosch EP, Deen HG Jr, Wilkens JA. Symptoms of 100 patients with electromyographically verified carpal tunnel syndrome. Muscle Nerve 1999;22:1448-56.

3. Margolis W, Kraus JF. The prevalence of carpal tunnel syndrome symptoms in female supermarket checkers. J Occup Med 1987;29:953-6.

4. Silverstein BA, Fine LJ, Armstrong TJ. Occupational factors and carpal tunnel syndrome. Am J Ind Med 1987;11:343-58.

5. de Krom MC, Knipschild PG, Kester AD, Spaans F. Efficacy of provocative tests for diagnosis of carpal tunnel syndrome. Lancet 1990;335:393-5.

6. Katz JN, Larson MG, Sabra A, Krarup C, Stirrat CR, Sethi $\mathrm{R}$, et al. The carpal tunnel syndrome: diagnostic utility of the history and physical examination findings. Ann Intern Med 1990;112:321-7.

7. Werner RA, Andary M. Electrodiagnostic evaluation of carpal tunnel syndrome. Muscle Nerve 2011;44:597-607.
8. Mathis LB, Gatchel RJ, Polatin PB, Boulas HJ, Kinney RK. Prevalence of psychopathology in carpal tunnel syndrome patients. J Occup Rehabil 1994;4:199-210.

9. Pogorzelski R, Kułakowska A, Halicka D, Drozdowski W. Neurological and emotional profile of carpal tunnel syndrome patients. Przegl Lek 2011;68:269-73. [Abstract]

10. Fernández-de-las-Peñas $\mathrm{C}$, Fernández-Muñoz JJ, PalaciosCeña M, Navarro-Pardo E, Ambite-Quesada S, SalomMoreno J. Direct and Indirect Effects of Function in Associated Variables Such as Depression and Severity on Pain Intensity in Women with Carpal Tunnel Syndrome. Pain Med 2015;16:2405-11.

11. Fernández-Muñoz JJ, Palacios-Ceña M, Cigarán-Méndez M, Ortega-Santiago R, de-la-Llave-Rincón AI, SalomMoreno J, et al. Pain is Associated to Clinical, Psychological, Physical, and Neurophysiological Variables in Women With Carpal Tunnel Syndrome. Clin J Pain 2016;32:122-9.

12. Jablecki CK, Andary MT, Floeter MK, Miller RG, Quartly CA, Vennix MJ, et al. Practice parameter: Electrodiagnostic studies in carpal tunnel syndrome. Report of the American Association of Electrodiagnostic Medicine, American Academy of Neurology, and the American Academy of Physical Medicine and Rehabilitation. Neurology 2002;58:1589-92.

13. Koldas Dogan S, Ay S, Evcik D, Baser O. Adaptation of Turkish version of the questionnaire Quick Disability of the Arm, Shoulder, and Hand (Quick DASH) in patients with carpal tunnel syndrome. Clin Rheumatol 2011;30:185-91.

14. Hisli N. Beck Depresyon Envanteri'nin geçerliği üzerine bir çalışma. Psikoloji Dergisi 1988;6:118-26.

15. Makanji HS, Zhao M, Mudgal CS, Jupiter JB, Ring D. Correspondence between clinical presentation and electrophysiological testing for potential carpal tunnel syndrome. J Hand Surg Eur Vol 2013;38:489-95.

16. Ring D, Kadzielski J, Malhotra L, Lee SG, Jupiter JB. Psychological factors associated with idiopathic arm pain. J Bone Joint Surg [Am] 2005;87:374-80.

17. Coggon D, Ntani G, Harris EC, Linaker C, Van der Star R, Cooper C, et al. Differences in risk factors for neurophysiologically confirmed carpal tunnel syndrome and illness with similar symptoms but normal median nerve function: a case-control study. BMC Musculoskelet Disord 2013;14:240.

18. Sucher BM, Schreiber AL. Carpal tunnel syndrome diagnosis. Phys Med Rehabil Clin N Am 2014;25:229-47.

19. Zeidman LA, Singh SK, Pandey DK. Higher diagnostic yield with the combined sensory index in mild carpal tunnel syndrome. J Clin Neuromuscul Dis 2014;15:143-6. 